\title{
Research on the Application of NFC Technology in Electronic Commerce Mobile Payment
}

\author{
Chunlei Han ${ }^{1, a}$, Fangfang $\mathrm{Liu}^{2, \mathrm{~b}}$ and Xia Hou${ }^{3, \mathrm{c}}$ \\ ${ }^{1}$ Qingdao Huanghai University, Qingdao 266427, China \\ achentongab@163.com, bchentongab@163.com, 'chentongab@163.com
}

Keywords: NFC payment; Mobile payment technology; Defect; Solutions.

\begin{abstract}
On December 18, 2015, Apple's official announced that apple began to cooperate with china Unionpay and launched apple pay in china, Unionpay cardholders can add their UnionPay card to the iphone, apple watch and ipad, and pay by using these intelligent terminal. NFC payments break the traditional mode of payment, change the user's habits of payment, enhance convenience of payment, reduce the cost of financial institutions, and speed up the flow rate of goods. Mobile payment technology has changed people's lives, but this new technology has large defects in these aspects: the laws and regulations, technical standards, infrastructure, security and so on. This paper describes these defects and proposes appropriate countermeasures.
\end{abstract}

\section{Introduction of NFC mobile payment technology and current situation.}

In recent years, with the rapid development of $4 \mathrm{G}$ networks and communication technology, people are dependent on modern wireless communications technology, and people's daily life is inseparable from smart phones and wireless networks, and short-range wireless communications technology has gradually been accepted. On December 18, 2015, apple's official announced that apple began to cooperate with china Unionpay and launched Apple pay in china. Apple pay is a kind of mobile payment function based on NFC(Near Field Communication), which officially launched in the US on October 20, 2014. With the release of apple pay, NFC payment becomes the focus of public attention once again.

NFC enters the commercial phase early. In 2010, Google had joined the NFC protocol in Android.Google had expected promotion by Google wallet NFC payment, but the effect is not ideal. The Nelson report shows that 37\% of American consumers who use NFC to pay, but the most popular mobile payment is still the QR code scanning. In 2010, China's three major telecom operators and China UnionPay launched NFC mobile payment services sequentially. They want to establish themselves as the core of the industrial chain. In 2012, China Mobile reached an agreement with China UnionPay, and the industry standard of NFC is $13.56 \mathrm{M}$ band. Since then the biggest obstacle in the domestic large-scale popularization of NFC is removed. In 2014, China Mobile planned to sell NFC mobile phones to 30 million, while China Telecom and China Unicom had also given appropriate subsidies for NFC mobile phones.

\section{The advantages and of NFC technology.}

NFC, Bluetooth, and infrared are common near-field payment technology. NFC payment has obvious advantages, mainly in the following aspects:

Short distance, low power consumption. NFC is a wireless connectivity technology which can provide a safe, efficient communication. It took a unique signal attenuation technology. The transmission range of other communication technology can reach several meters or even hundreds of meters, but the transmission distance of NFC devices does not exceed $20 \mathrm{~cm}$. So it consumes relatively low energy.

NFC technology is much safer. NFC is a short-range connectivity technology which offers short distance communication between several devices. Compared with other connections, NFC is a kind of 
confidential communication. SE security chip built in NFC card or terminal can ensure security through key authentication. The communication is more secure combined with its close distance and small RF range.

NFC and other near-field payment technology complement with each other.The NFC function has become formally standard with more and more manufacturers' support. A lot of contactless smart cards are compatible with NFC technology. As an emerging technology, NFC's goal is not to replace Bluetooth, Wi-Fi and other wireless technologies, but to play a complementary role on different occasions and areas. NFC uses a trading mechanism for consumers, and it is more reliable and simpler than other communication. NFC is a short-distance trading for the exchange of financial information or sensitive personal information and other important data, but other means of communication can complement insignificance of NFC communication distance, for they are suitable for long distance data communications.

\section{The problems of NFC technology.}

In early 2000, mobile network operators began to explore the concept of mobile payments, but did not achieve effective progress. Japan and South Korea has shown a good momentum of mobile payments development, but the development of global mobile payments has been in a state of slow growth for a long time. China is one of the countries who use mobile payment earlier, but until 2011 the mobile payment application is still small. The market is difficult to significantly expand. The main reasons are:

Lack of near field payment application infrastructure.Near-field payment requires two terminals: one is a mobile terminal with NFC function, and the other one is merchant terminal which can support mobile payment capabilities. In addition to the two terminals, payment process also needs a complete and secure mobile payment information system. Construction of information systems require banks, communications operators, NFC hardware and software manufacturers to work together. At present, the mobile phone and the terminal which can install technology of NFC are very small, while there is the lack of software applications for mobile payment.

Technical standards are not uniform. When the near-field payment technology started, communication operators and UnionPay have competitive relation, and they have developed their own mobile payment technology standards which seriously affected the development of mobile payment.

The Consumer's habit of using mobile payment has not yet formed. With the mobile payment technology developing rapidly, the majority of domestic users just develop the habits of using of third-party payment platform for payment. They doubt about the new payment method, and do not trust and accept this payment, which provides obstacles for users to use near-field payments.

The problem of credit system. When users use mobile payment services, the first consideration is the security of the transaction.

Thus, when users use the mobile near-field payment, financial institutions need to share the risk of the users so that users can reassure themselves to use it. Users are lack of enthusiasm about using mobile payment for China is lack of laws and regulations about the mobile near-field payment.

\section{Application of NFC Technology.}

For smart media.You simply need to make NFC phone close to the smart media, you can get useful information and download by using the phone's NFC reader. Businesses embed a low-cost RFID label in such smart media, users only need to put NFC phone close to the RFID label, you can read the information, and then start the service request by using NFC mobile. The user can find a variety of services in the mobile Internet. The service provider can provide advertising, information inquiry, online shopping and other services by using the RFID label. For example, when people are 
waiting for the bus in the station, they use NFC phones induce RFID label on a bus stop sign, they will be able to obtain real-time bus arrival information.

For near-field payment.With the continuous development of NFC near-field payment technology, more and more mobile phones support NFC function. While the mobile phone has become a necessary tool for daily life, the mobile phone has become the medium of payment by NFC software and hardware technology. Users only need to install the NFC software in the mobile phone wallet, add the personal name of the bank card after real name authentication, set the corresponding fingerprint, voice and digital password. When paying for something, users only need to open the NFC function and put the mobile phone close to the NFC terminal. Then the terminal can identify the personal information, and pay after entering the password.

For electronic proof of identity.Electronic identification is actually an electronic access, and the user can apply for permission. Users complete the purchase of the electronic ticket after putting the phone near the automatic ticketing terminal. So it is very convenient for users. After confirming the payment of the user, electronic access certificate will be automatically transmitted to the user's mobile NFC phone or security chip. When it's the time of admission, users only need to put the NFC mobile phone near the entrance of reader terminal. The user is allowed to enter after the reader terminal check the electronic ticket. This approach saves the cost of paper bills and improve the quality of service.

The establishment of the residents' daily life card.Service life is closely linked with the common people and electronic, mobile, and interactive network is also a trend of service life. So we should improve the convenience of residents' daily life and it is the duty of the government. To establish authentication infrastructure through the use of mobile phones based on NFC technology, build the cloud storage and the cloud computing platform for the smart city, access to all kinds of identification equipment (consumer, campus card, health care, public facilities, etc.), provide a feasible technical means for cross platform data sharing to across information gap. The platform will enhance personal application experience in health care, education and training, transportation, security and other fields, so that the construction of smart city truly serve the people's livelihood, and bring new opportunities for the development of various industries.

\section{Thinking on the development of NFC Technology.}

The application of NFC industrial chain.It can be expected that the development of NFC technology will lead to the development of a large number of related industries, form a complete and sizeable NFC industry chain, and produce great economic benefits.

NFC industry chain mainly includes the following participants:

Content providers: NFC content providers provide a full range of services for mobile users, users can access the relevant information through reading electronic posters, magazines etc.

Terminal manufacturers: Chip manufacturers produce NFC chip and related interface and accessories, terminal manufacturers produce NFC intelligent mobile phone on the basis of the NFC chip. With the jointly promotion of technological progress and market demand, NFC smart phones will have more and more functions and high added value.

Device manufacturer: A large number of businesses need to install special NFC card reader in the subway, bus and public places such as cinemas, NFC equipment manufacturers can obtain high profits.

Telecom operators: By providing mobile network, mobile phone recharge, identification and search services for users, telecom operators can gain more benefits.

Financial Institutions: Financial institutions and mobile operators develop the NFC business model together, and obtain more market share through active exploration and development of NFC business.

The success of the NFC industry chain requires enterprises to actively participate, work together and jointly develop new profit model, then share market share. At present, many enterprises have shown a keen interest in the development of NFC technology. 
Countermeasures for the development of NFC Technology.Take various measures to develop consumer habits: Because of the long-term use of cash, credit card and bank card, the transition of old habits to a new way need strong external drive. There are two main types of measures. A measure is continuing to create a sense of fashion on the mobile phone near-field payments, using celebrity endorsement, stimulate consumer fashion psychology. The special measures will help to consolidate the user's continuance intention; another measure is discount strategies, such as free card, consumer purchase, discount points, etc to change habits of consumer payment. This kind of measure helps make the potential consumer to be converted to the actual consumers.

Reducing the distrust of consumer: Although the near field payments improve payment efficiency, bring great convenience to consumers, in the face of this new payment method, we should eliminate distrust and psychological barriers of consumers fundamentally. Mobile operator, bank, mobile phone manufacturers should increase publicity of near-field payment technology, fully explain the near-field payment processes, payment security technology measures, establish risk protection measures and accounts for the compensation system, so that consumers fully understand the reliability and availability of the technology.

Develop new mobile payment applications and innovative business models: Mobile payment application is relatively small. We should intensify the development of mobile payment applications, payment to improve the stability, reliability and operability of system .Variety of value-added services based on mobile payments are small, and the potential of consumer consumption is not fully tapped. Therefore, the mobile payment service providers should fully analyze the consumer psychology and the characteristics of the industry, develop mobile payment products, attract consumers and promote the development of the industry.

Strict formulation of the mobile payment industry standards and market access system, encourage cooperation and win-win: The relevant state departments should formulate mobile payment industry standards and market access system strictly. The State shall stipulate the corresponding qualification of commercial institutions, banks, payment platform operators, mobile operators and other subjects which participate in the near field of payment technology development and application. The state should develop scientific principles of market access on mobile payment industry, but should not be set higher barriers to market access, and should encourage payment operators which have good credit payment to participate in, enliven the mobile payment market, encourage win-win cooperation among the participants, develop common standards in the field of mobile payment.

\section{Summary}

With the progress of technology, the number of mobile transactions and a huge amount of users prompt the rapid development of NFC payment. At the same time, the industry operation mode is gradually mature. Although consumers have doubts about the safety of mobile technology, the development of technology has improved security greatly. The smart phones and near-field payment hardware are developing, and two-dimensional code, mobile APP and other end products continue to enrich, NFC pay more attention to the user experience, which allows users to have a quality upgrade in NFC pay experience.

\section{References}

[1]. Lu Han, Yalou Sang. NFC technology and its application. Mobile Communications. Vol. 24 (2008) No. 6, p. 25-28.

[2]. Hao Tian. The practice and optimization of near field mobile phone payment. Financial Computer of China. Vol. 12 (2014) No. 3, p. 26-29.

[3]. Zhihua Zhang, Ling Huang. Analysis of the application of NFC near-field payment. Silicon Valley. Vol. 172(2015) No. 4, p.160-161. 
[4]. Yanping Chen. Central bank built certification system to promote the application of NFC near field payment. Communication information newspaper. Vol. 24 (2014) No. 15, p. 15-16.

[5]. Ran Zhang, Jiaxiang Wei. Application of NFC technology in bank's new mobile payment Era.Modern Business. Vol. 36 (2012) No. 5, p. 153-154. 